\title{
Use of cross-linked carboxymethyl cellulose for soft-tissue augmentation: preliminary clinical studies
}

\author{
Mauro Leonardis' \\ Andrea Palange ${ }^{2}$ \\ Rodrigo FV Dornelles ${ }^{3}$ \\ Felipe Hund ${ }^{4}$ \\ 'Department of Plastic Surgery, \\ Salvator Mundi International \\ Hospital, Roma, Italy; ${ }^{2}$ Department \\ of Aesthetic Medicine, Fisiobios, \\ Roma, Italy; ${ }^{3}$ Department of Plastic \\ Surgery, Núcleo de Plástica Avançada, \\ São Paulo, SP, Brazil; ${ }^{4}$ Department \\ of Plastic Surgery, Consultorio de \\ Cirurgia Plastica, Criciuma, SC, Brazil
}

Correspondence: Mauro Leonardis Salvator Mundi International Hospital, Viale delle Mura Gianicolensi, 67-00I00 Roma, Italy

$\mathrm{Tel}+3906588961$

Fax +390658896023

Emailmleonardis@virgilio.it
This article was published in the following Dove Press journal:

Clinical Interventions in Aging

8 November 2010

Number of times this article has been viewed

Purpose: The continual search for new products for soft-tissue augmentation has in recent years led to the introduction of long lasting alternatives to hyaluronic acids and collagen that are composed of other polymers able to improve clinical persistence over time. This is the first report in which sodium carboxymethyl cellulose (CMC) has been chemically treated by the cross-linking process and thus used as a hydrogel for soft-tissue augmentation through injection with thin needles. The study evaluates, from a clinical point of view, the behavior of cross-linked carboxymethyl cellulose hydrogel used in the aesthetic field and its side effects so as to check the safety and performance of the polymer following intradermal injections.

Patients and methods: This work shows the preliminary results of an ongoing clinical study conducted between 2006 and 2009, performed on 84 healthy volunteers (62 females, 22 males) aged between 18 and 72 years, for the treatment of 168 nasolabial folds, 45 perioral wrinkles, and 39 lip volume.

Results: Study results show an excellent correction of facial defects. Tolerance and aesthetic quality of the correction obtained indicate considerable safety features and absence of side effects. From a clinical point of view, hydrogel is gradually absorbed into the injection site without migration issues.

Conclusion: Cross-linked CMC hydrogel proves to be an ideal agent for soft tissue augmentation with regard to safety and ease of application. It did not cause infection, extrusion, migration, or adverse reactions in the patients who have been followed for two years. Delayed aesthetic results on facial wrinkles were very satisfactory.

Keywords: dermal fillers, facial aging, cosmetic, hyaluronic acid, facial wrinkles, facial fold

\section{Introduction}

The first injectable heterologous implants date back to 1889 with the introduction of paraffin in humans. Because of the important side effects produced, such as pulmonary embolism, granulomas, and "paraffinoma", paraffin was abandoned. ${ }^{1}$ The use of liquid silicone was evaluated from 1961 in the medical field and was successively extended to the area of aesthetics. ${ }^{1,2}$ At the beginning of 20th century, fat autologous implants and lipofilling started to be used. ${ }^{3,4}$ Since 1970, new technologies have allowed the reduction of the immunogenic potential of bovine collagen, used for the correction of wrinkles and scars. ${ }^{1,5,6}$ In 1985, different types of collagen were introduced to the market, ${ }^{7}$ followed by other substances, such as hyaluronic acid, ${ }^{8,9}$ known generically as dermal fillers. ${ }^{10-12}$

Hyaluronic acid and collagen fillers are short-acting. Clinical results disappear quickly and may require subsequent applications in order to maintain the aesthetic 
results. ${ }^{13}$ Therefore, long lasting alternative substances such as calcium hydroxylapatite ${ }^{14,15}$ and poly-L-lactic acid ${ }^{14,16}$ have appeared with increasing results in recent years. ${ }^{17}$ However, these products have significant limitations. They often cause reactive fibrosis of tissues and are only indicated for filling into deep tissues. If injected in mid or superficial dermis they frequently produce ulcers and granulomas. ${ }^{18,19}$ Generally they prove less manageable than hyaluronic acids and collagen, which instead allow a wider range of use.

Carboxymethyl cellulose (CMC) is a biosynthetic substance neither animal nor human, ${ }^{20}$ already present in its native state in some dermal fillers with carrier ${ }^{15,16}$ or filling function associated with other polymers. ${ }^{21}$

This is the first report in which CMC has been chemically treated by the cross-linking process and thus used as a hydrogel for soft tissue augmentation through injection with thin needles.

This study evaluates, from a clinical point of view, the behavior of cross-linked carboxymethyl cellulose hydrogel used in the aesthetic field and its side effects so as to check the safety of the polymer following intradermal injections.

\section{Material and methods Preparation of cross-linked carboxymethyl cellulose hydrogel}

The preparation of the polymer was carried out by using pharmacological grade sodium carboxymethyl cellulose, chemically treated with 1,4-Butanediol diglycidyl ether cross-linking and subjected to multiple stages of diafiltration. The purified polymer was therefore suspended in saline solution, put in $1 \mathrm{~mL}$ syringes and sterilized air-steam cycle at 121 degrees. The preparation of tests was performed in Italdevice Srl Laboratories (Pomezia, Italy), which are certified for the preparation of pharmaceutical and medical devices.

The tested product does not contain preservatives such as parabens and color additives or any substance prohibited by the $\mathrm{FDA}^{22}$ and $\mathrm{EEC}^{23}$ regulations. Substances contained in the formula are present in the amounts approved by the International Pharmacopoeia.

\section{Specifications of cross-linked carboxymethyl cellulose hydrogel}

Hydrogel, prepared according to this procedure and used for this experiment, showed pH of 7.4 and osmolarity of 318 . $\mathrm{CMC}$ concentration was $20 \mathrm{mg} / \mathrm{g}$ and hydrogel particles were about 500 microns (485-519 microns) and allowed easy injection with $271 / 2 \mathrm{G}$ and $301 / 2 \mathrm{G}$ needles.

Rheometric tests for rheology realized at $25^{\circ}, 1 \%, 1 \mathrm{~Hz}$, were: a) oscillatory $\left(25^{\circ} ; 1 \mathrm{~Hz}\right)$ vs deformation amplitude $0.1 \%-1000 \%$; b) oscillatory $\left(25^{\circ} ; 1 \%\right)$ vs frequency $0.1-40 \mathrm{~Hz}$; c) flow $\left(25^{\circ} ; 3 \mathrm{~min}\right)$ vs velocity $0.1-4 \mathrm{~S}^{-1}$, and showed: phase angle $(\delta)$ of $28^{\circ}$, storage (elastic) modulus $\left(\mathrm{G}^{\prime}\right)$ of $70 \mathrm{~Pa}$, viscous (loss) modulus (G”) of $35 \mathrm{~Pa}$, viscosity ( $\eta$ ) of 380 Pa-s. These tests determine: a) maximum load applied to the gel without loss of mechanical property, which was $30 \%$; b) viscoelasticity, investigating the liquidsolid behavior of the hydrogel at various conditions, which showed a predominantly solid behavior at all frequencies investigated; c) phase angle, showed no change in the elastic and viscous properties, modifying the frequencies. These studies showed a material whose structure is very strong even at high deformation, with an identical variation of its elastic and viscous properties at different stress conditions applied (Figures 1 and 2).

Tests were repeated using cellulase enzyme to break the cross-linked network of the gel, after putting into gas chromatography on column injection, to assess the fraction of the cross-linking residual agent remaining in the hydrogel that was lower than one part per million.

All of tests were performed in Laboratories Italdevice Srl (Pomezia, Italy).

\section{Clinical tests}

This study was performed on 84 healthy volunteers (62 females, 22 males) aged between 18 and 72 years, (average 44.3), subjected to informed consent about the procedure, which was undertaken by four independent medical specialists in office-based surgery centers of São Paulo and Porto Alegre (Brazil). The study, conducted in accordance with the Declaration of Helsinki, was approved by respective ethic and research committees in

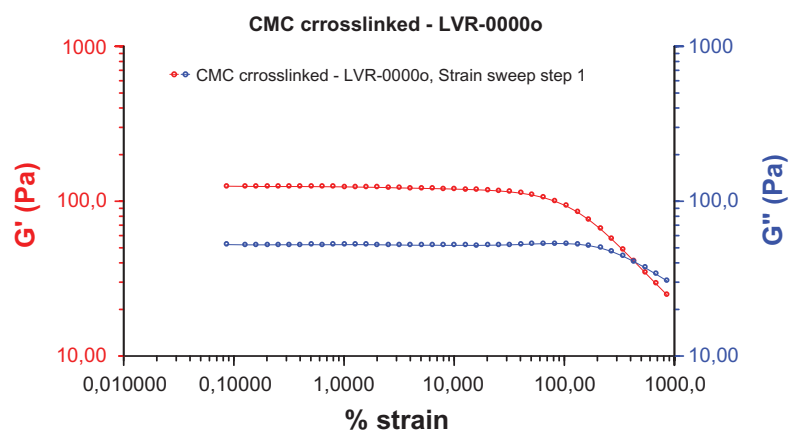

Figure I Strain sweep step: elastic modulus G' and loss modulus G" versus frequency. 


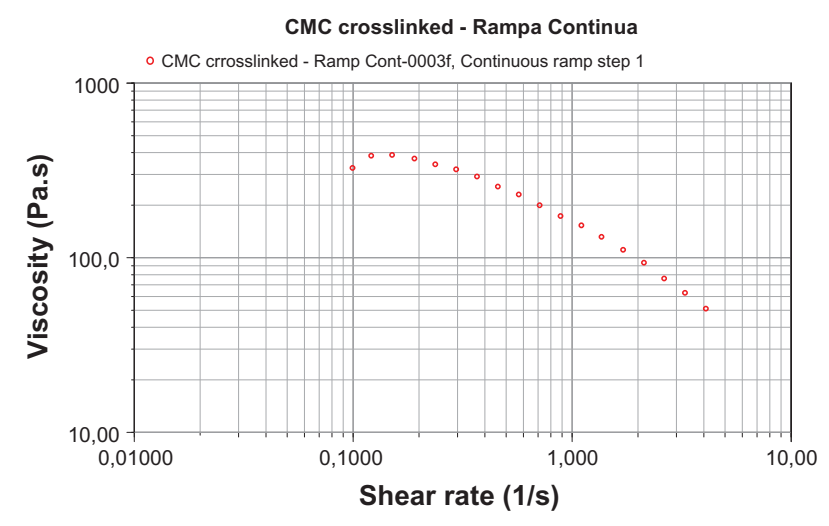

Figure 2 Flow test - continuous ramp step: rotational viscosity versus shear rate.

the participating research centers and lasted from June 2006 to March 2009.

People excluded from the tests were: pregnant women, patients younger than 18 years, patients with a tendency to develop hypertrophic and keloid scars, patients with burned skin or undergoing radiotherapy, patients taking aspirin and anticoagulants, patients with inflammation or infection of the area to be treated.

\section{Protocol execution of tests}

Two weeks before treatment, an intradermal skin test was performed by injecting $0.05 \mathrm{~mL}$ of cross-linked CMC hydrogel in the forearm of each patient in order to check local tolerance to the product. Only volunteers in good health with healthy and intact skin were chosen for the experiment. The application was preceded by asepsis with $70 \%$ alcohol solution.

According to the degree of wrinkle or defect to be corrected, the protocol included one or two treatment sessions, seven days apart, in which the maximum amount of the product used for each site of infiltration should not have exceeded $1 \mathrm{~mL}$.

All tests were performed by injecting CMC into mid and deep dermis according to the end use of this device, as suggested by researchers. The effectiveness of treatment was evaluated on the basis of the double assessment of doctors and patients. The evaluation scale was organized as follows:

- Index of patients satisfaction in analogical scale: dissatisfied $>$ without visible changes $>$ satisfied $>$ very satisfied

- Degree of efficacy in doctors opinion:

A: aggravation after treatment; B: without visible changes; C: sufficient results; D: good results; E: excellent results.
The evaluation of results had been made on one or more defects per patient, before and after each treatment session. A subsequent assessment was performed four weeks after the last injection. The final evaluation was achieved after 6 months and after 9 months.

\section{Evaluation of adverse reactions}

Side effects were analyzed 15 minutes, 1 hour, and 24 hours after treatment in all patients, especially those showing redness of the treated area. Patients were examined by a retrospective analysis for signs of erythema and edema and assessed by scores 15 minutes, 1 hour, and 24 hours after injection. Reactions are recorded in Table 1 . The scores of the adverse reactions were obtained by calculating the average value of erythema and edema. Results were compared with reactivity indices presented in Table 2 .

\section{Results}

Eighty-four patients had been treated and followed for the injection of 168 nasolabial folds, 45 perioral wrinkles, and 39 lip volume, from June 2006 to March 2009. All patients were followed until March 2008 to verify the maintenance of the aesthetic result, but only 64 were further monitored over time until March 2009 (2 years follow-up) so as to check the occurrence of some unexpected event after the total absorption of the CMC. Twenty patients were re-injected after one year from the first treatment (from October 2007 and March 2009). For this group of patients long-term studies are still ongoing.

Patients through the analogical scale of results positively assessed acceptability of treatment. The satisfaction index exceeded $90 \%$ (see Table 3). After treatment, doctors found excellent results in $80 \%$ of cases (see Table 4). Patients considered the results very satisfactory in $85 \%$ of cases for nasolabial folds, perioral wrinkles, and lip volume. All treated cases showed the decrease of defect depth from the first infiltration, sometimes the complete resolution of wrinkles. Doctors and patients expressed similar opinions on the quality

Table I Intradermal reactivity scores from a clinical point of view

\begin{tabular}{|c|c|c|c|}
\hline Erythema & Scores & Edema & Scores \\
\hline No erythema & 0 & No edema & 0 \\
\hline Slight erythema & I & Very slight edema & I \\
\hline $\begin{array}{l}\text { Clearly visible } \\
\text { erythema }\end{array}$ & 2 & Slight edema & 2 \\
\hline Moderate erythema & 3 & $\begin{array}{l}\text { Moderate edema about } \\
\text { I mm raised skin }\end{array}$ & 3 \\
\hline Marked erythema & 4 & Strong extended edema & 4 \\
\hline
\end{tabular}


Table 2 Reactivity indices (Draize classification)

\begin{tabular}{ll}
\hline Index & Classification \\
\hline$<0.5$ & Non reactive \\
$0.5-2.0$ & Slightly reactive \\
$2.0-5.0$ & Moderately reactive \\
$5.0-8.0$ & Highly reactive \\
\hline
\end{tabular}

of correction and stability over time, regardless of the type of treated wrinkles (Figures 3, 4 and 5). The results remained constant for 6 months in most patients. One patient in ten showed a more rapid decrease of the correction without returning to the initial condition. During this period the index of patient satisfaction, after six months, was between "satisfied" and "very satisfied, regardless of the type of corrected wrinkles.

Nine months after the first treatment the results were still good. The variations obtained with respect to the initial condition were judged positively in most cases. After one year results remain satisfactory for one third of patients.

\section{Observed adverse effects}

About one patient in ten underwent anesthesia. A nonspecific slight erythema was noted in less than $1 / 5$ of treated patients (14 patients) on injection with spontaneous regression after 1-36 hours. No granulomas appeared early or late $(0 \%)$. There was no infection $(0 \%)$, extrusion $(0 \%)$, or migration $(0 \%)$ confirming the possibility of immediate and safe treatment without preliminary tests.

\section{Local and systemic tolerance}

The results of the observed data are presented in Table 5.

\section{Discussion}

Carboxymethyl cellulose (CMC) is a biosynthetic substance based on the b-(1-4)-D-glucopyranose polymer of the cellulose, neither animal nor human. ${ }^{20}$ The available literature shows that $\mathrm{CMC}$ is an inert substance extremely safe and free of mutagenic or carcinogenic outcomes. ${ }^{24}$ Some studies underline a bactericidal effect within the

Table 3 Index of patients satisfaction

\begin{tabular}{lllll}
\hline Follow up & \multicolumn{3}{l}{ Index of patients satisfaction } \\
\cline { 2 - 5 } & Dissatisfied & $\begin{array}{l}\text { Without } \\
\text { visible } \\
\text { changes }\end{array}$ & Satisfied & $\begin{array}{l}\text { Very } \\
\text { satisfied }\end{array}$ \\
\hline 4 weeks & 0 & 2 & II & 71 \\
6 months & 0 & 2 & 50 & 32 \\
9 months & 0 & 2 & 58 & 24 \\
\hline
\end{tabular}

Table 4 Degree of efficacy in doctors opinion

\begin{tabular}{llllll}
\hline Follow & \multicolumn{4}{l}{ Degree of efficacy in doctors opinion } \\
\cline { 2 - 6 } up & $\begin{array}{l}\text { Aggravation } \\
\text { after } \\
\text { treatment }\end{array}$ & $\begin{array}{l}\text { Without } \\
\text { visible } \\
\text { changes }\end{array}$ & $\begin{array}{l}\text { Sufficient } \\
\text { results }\end{array}$ & $\begin{array}{l}\text { Good } \\
\text { results }\end{array}$ & $\begin{array}{l}\text { Excellent } \\
\text { results }\end{array}$ \\
\hline 4 weeks & 0 & $\mathrm{I}$ & 4 & 12 & 67 \\
6 months & 0 & $\mathrm{I}$ & 8 & 26 & 49 \\
9 months & 0 & $\mathrm{I}$ & 56 & 27 & 0 \\
\hline
\end{tabular}

tissues, thus making the substance absolutely safe. ${ }^{25}$ Presently, the growing success of hyaluronic acid for tissue filling is probably due to the possibility of direct injection without preliminary skin tests. ${ }^{26}$ Compared to old collagen it proves handy and easy to apply. ${ }^{20}$ However, hyaluronic acid have solution-like behavior at rheology low frequency ${ }^{21}$ and its properties help tissue repair. It also has anti-inflammatory functions but no filling function. Chemically treated by the cross-linking process, hyaluronic acid turns more pseudoplastic and suitable for dermal filling, ${ }^{8}$ although it does not conceptually present specific characteristics to that.

The choice of CMC for this study is based on the fact that this polymer has got, in its native state, specific characteristics for visco-supplementation, densification, and drug delivery. ${ }^{20}$ These properties have been received over the last 50 years by pharmaceutical companies that still use CMC as a high purity excipient for cortisone injections (dexamethasone) or an agent of delay (drug delivery) for the release of active principles (nifedipina).

Furthermore, $\mathrm{CMC}$ can produce tissue filling already in its native state. Some fillers (Radiesse ${ }^{\circledR}$, BioForm Medical, Inc, USA; Sculptra ${ }^{\circledR}$, Sanofi-Aventis Spa, IT; Laresse ${ }^{\mathrm{TM}}$, FzioMed, Inc, USA) use CMC with carrier or filling function. $15,16,21$

Despite having higher filling qualities than native hyaluronic acids, the native CMC (ie, non cross-linked), has got lower performance characteristics than crosslinked hyaluronic acids. Therefore the companies that until now have tried to use the native $\mathrm{CMC}$ for tissue filling
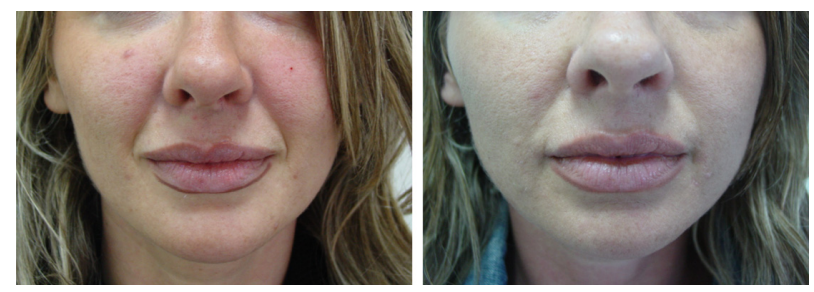

Figure 3 Before (left) and one month after (right) treatment of nasolabial folds with I $\mathrm{mL}$ of cross-linked CMC for each side. 

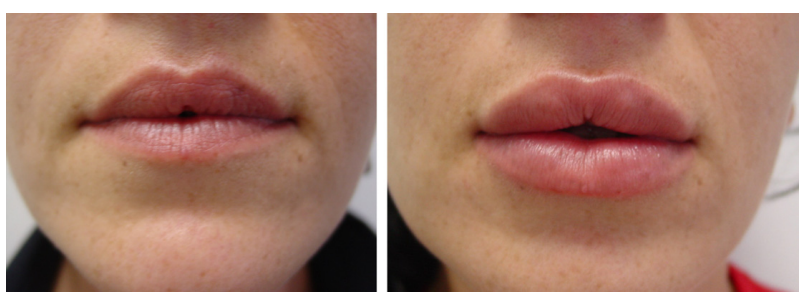

Figure 4 Before (left) and one month after (right) the treatment of upper and lower lips with $2 \mathrm{~mL}$ of cross-linked CMC.

had to add it to other synthetic substances. Here are two examples:

a. dermal filler composed of native carboxymethyl cellulose with addition of polyethylene oxide (Laresse ${ }^{\mathrm{TM}}$, FzioMed, Inc, USA); ${ }^{21}$

b. dermal filler with hydroxyapatite microspheres in a carrier gel composed of carboxymethyl cellulose and liquid glycerine (Radiesse ${ }^{\circledR}$, BioForm Medical Inc, USA). ${ }^{15}$

This is the first report in which free CMC has been chemically cross-linked and used as a hydrogel for soft-tissue augmentation through injection with thin needles. The results of the rheometric studies show that cross-linked CMC is extremely stable and mostly solid at all observed frequencies while passing through $271 / 2 \mathrm{G}$ and $301 / 2 \mathrm{G}$ needles. It also preserves handling characteristics comparable to those of hyaluronic acids.

This work reports the preliminary results of an ongoing clinical study conducted between 2006 and 2009. Study results show excellent correction and duration of effect. Tolerance and aesthetic quality of the correction obtained indicate considerable safety features and absence of side effects. Cross-linked CMC has been well received by doctors and patients with regard to facial wrinkles and folds.

The absence of allergic reaction $(0 \%)$ and the optimal tolerance allow immediate treatment of patients without a skin-test. The polymer has no derivatives of human or animal tissue and its formulation is made up of polysaccharides without protein and immunogenic residues.

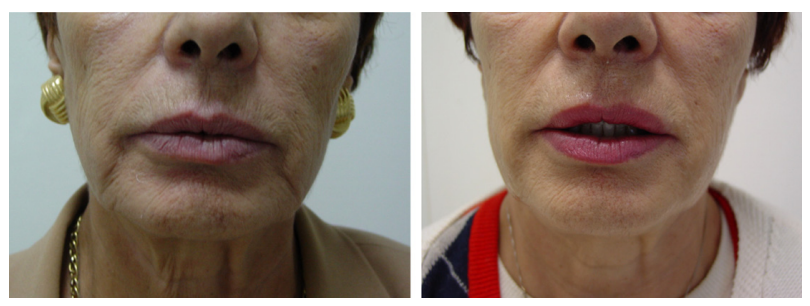

Figure 5 Before (left) and one month after (right) the treatment of perioral wrinkles (marionette lines and oral commissures) with $2 \mathrm{~mL}$ of crosslinked CMC.
Table 5 Reactions of edema and erythema observed

\begin{tabular}{llll}
\hline & I5 minutes & I hour & $\mathbf{2 4}$ hours \\
\hline Erythema & 0.17 & 0.13 & 0.05 \\
Edema & 0.00 & 0.00 & 0.00 \\
\hline
\end{tabular}

Note: Limits under which the product is classified non reactive: 0.5 (clinical scores see Table I).

The re-injection performed on the same site of the first infiltration does not produce side effects in the short- and long-term. The re-injection aiming at additional correction of wrinkles requires a few days off after the first application.

The persistence of the hydrogel has been demonstrated within the tissue injected in dermal areas. From a clinical point of view, hydrogel is gradually absorbed into the injection site without migration issues. The polymer can be injected with very thin needles $(301 / 2 \mathrm{G})$ confirming the absolute flexibility and manageability of cross-linked CMC hydrogel.

\section{Conclusion}

In conclusion, cross-linked CMC hydrogel proves to be an ideal agent for facial wrinkles with regard to safety and ease of application. It did not cause infection, extrusion, migration, or adverse effects in the patients who have been followed for two years (some of them were monitored for a further 12 months after the total re-absorption of the polymer). A slight erythema visible as redness was noted only in few patients and disappeared within an acceptable term (1-36 hours). Delayed aesthetic results on facial wrinkles were very satisfactory.

\section{Acknowledgments}

Special thanks to Italdevice Srl (Pomezia, Italy) for preparation of the tests. Thanks to Professor Pedro DE Martins (Porto Alegre-RS, Brazil) and Dr Andè Muccini (Passo Fundo-RS, Brazil) for the advice and help to perform the treatments.

\section{Disclosure}

The present study has no commercial purposes. The authors report no conflict of interest in this work.

\section{References}

1. Matton G, Anseeuw A, Dekeyser F. The history of injectable biomaterials and the biology of collagen. Aesthetic Plast Surg. 1986;60:898-905.

2. Webster RC, Fuleihan NS, Hamdan US, et al. Injectable silicone: report of 17,000 facial treatments since 1962. Am J Cosmetic Surg. 1986;3: 41-48.

3. Horl HW, Feller AM, Biemer E. Technique for liposuction fat reimplantation and long term volume evaluation by magnetic resonance imaging. Ann Plast Surg. 1991;26:248. 
4. Coleman SR. Long term survival of fat transplants: controlled demonstrations. Aesthetic Plast Surg. 1995;19:421-425.

5. Charriere G, Bejot M, Schnitzler LR. Reactions to a bovine collagen implant. Clinical and immunological study in 205 patients. $J$ Am Acad Dermatol. 1989;21:1203-1208.

6. Knapp TR, Kaplan EN, Daniels JR. Injectable collagen for soft tissue augmentation. Plast Reconstr Surg. 1977;60:398.

7. Knapp TR, Vistnes LM. The augmentation of soft tissue with injectable collagen. Clin Plast Surg. 1985;12:212.

8. Balazs EA, Denlinger JL, Leshchiner E, Band Larsen N, Leshchiner A, Morales B. Hylan: hyaluronan derivatives for soft tissue repair and augmentation. Biotech. 1988;442-445.

9. Fernandez EM, Mackley CL. Soft tissue augmentation: a review. J Drugs Dermatol. 2006;5:630-641.

10. Baumann L. Dermal fillers. J Cosmet Dermatol. 2004;3(4):249-250.

11. Carruthers J, Cohen SR, Joseph JH, Narins RS, Rubin M. The science and art of dermal fillers for soft-tissue augmentation. J Drugs Dermatol. 2009;8(4):335-350.

12. Vedamurthy M, IADVL Dematosurgery Task Force. Standard guidelines for the use of dermal fillers. Indian J Dermatol Venereol Leprol. 2008;74 Suppl:S23-S27.

13. Robinson JK, Hanke CW. Injectable collagen implant: histopathologic identification and longevity of correction. J Dermatol Surg Oncol. 1985; 11:124-130.

14. Fernandez EM, Mackley CL. Soft tissue augmentation: a review. J Drugs Dermatol. 2006;5(7):630-641.

15. Ridenour B, Kontis TC. Injectable calcium hydroxylapatite microspheres (Radiesse). Facial Plast Surg. 2009;25(2):100-105. Epub 2009 May 4.

16. Keni SP, Sidle DM. Sculptra (injectable poly-L-lactic acid). Facial Plast Surg Clin North Am. 2007;15(1):91-97.

17. Jacovella PF, Peiretti CB, Cunille D, Salzamendi M, Schechtel SA. Long-lasting results with hydroxylapatite (Radiesse) facial filler. Plast Reconstr Surg. 2006;118 Suppl 3:15S-21S.
18. Sankar V, McGuff HS. Foreign body reaction to calcium hydroxylapatite after lip augmentation. J Am Dent Assoc. 2007;138(8):1093-1096.

19. Hamilton DG, Gauthier N, Robertson BF. Late-onset, recurrent facial nodules associated with injection of poly-L-lactic acid. Dermatol Surg. 2008;34(1):123-126. Epub 2007 Dec 5.

20. Gruzman MK, Bashura GS. Rheolocic properties of sodiumcarboxymethyl cellulose and methylcellulose. Farm Zh. 1964;19: 53-58.

21. Falcone SJ, Doerfler AM, Berg RA. Novel synthetic dermal fillers based on sodium carboxymethylcellulose: comparison with crosslinked hyaluronic acid-based dermal fillers. Dermatol Surg. 2007;33 Suppl 2: S136-S143.

22. US Food and Drug Administration. Ingredients prohibited and restricted by FDA regulations. Accessed 2010 Oct 08 . Available from: http://www.fda.gov/Cosmetics/ProductandIngredientSafety/Selected CosmeticIngredients/ucm127406.htm

23. European Commission. Cosmetics directive. Accessed 2010 Oct 08. Available from: http://ec.europa.eu/consumers/sectors/cosmetics/ documents/directive/index_en.htm

24. McElligott TF, Hurst EW. Long-term feeding studies of methyl ethyl cellulose ('Edifas'A) and sodium carboxymethyl cellulose ('Edifas'B) in rats and mice. Food Cosmet Toxicol. 1968;6(4):449-460

25. Keipert S, Voigt R. Interactions between macromolecular adjuvants and drugs. Part 18: The binding behaviour of sodium carboxymethylcellulose and other macromolecules towards streptomycin sulphate. Pharmazie. 1979;34(9):548-551.

26. Larsen NE, Pollack CT, Reiner K, Leshchiner E, Balazs EA. Hylan gel biomaterial: dermal and immunologic compatibility. J Biomed Mater Res. 1993;27:1129-1134.
Clinical Interventions in Aging

\section{Publish your work in this journal}

Clinical Interventions in Aging is an international, peer-reviewed journal focusing on evidence-based reports on the value or lack thereof of treatments intended to prevent or delay the onset of maladaptive correlates of aging in human beings. This journal is indexed on PubMed Central, MedLine, the American Chemical Society's 'Chemical Abstracts Ser-

\section{Dovepress}

vice' (CAS), Scopus and the Elsevier Bibliographic databases. The manuscript management system is completely online and includes a very quick and fair peer-review system, which is all easy to use. Visit http://www.dovepress.com/testimonials.php to read real quotes from published authors. 